\title{
COVID-19 performance index for spatial assessment of pandemic management in India
}

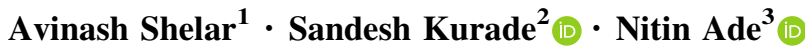

Received: 24 May 2021 / Revised: 13 October 2021/ Accepted: 16 October 2021/Published online: 11 November 2021

(C) Korean Spatial Information Society 2021

\begin{abstract}
The novel coronavirus disease 2019 (COVID19) pandemic disaster has been ongoing worldwide and so far in India for more than a year now. World Health Organization declared the COVID-19 as a pandemic in March 2020. The word "pandemic" is used as a worldwide spread of any new disease. The disease had affected more than 200 countries around the world. The present study seeks to assess the anti-pandemic measures taken by states and union territories (UTs) of India. In this regard, COVID19 Performance Index (CPI) has been developed on the basis of aggregate and per capita confirmed cases, deaths and tests of COVID-19. It gives an instrument to compare the regions of India on their efforts to handle the pandemic. Using CPI, the states and UTs of India have been spatially assessed. Economic and demographic factors which are responsible for the transmission of coronavirus disease have taken into consideration for the spatial assessment of the performance of states and UTs. From results we found that, the average CPI across all states and UTs of India excluding Lakshadweep is 52.69 CPI for 21 states and UTs out of 35 are below the average CPI. The correlation test
\end{abstract}

Nitin Ade

ni3ade@gmail.com

Avinash Shelar

avishelar@gmail.com

Sandesh Kurade

sandeshkurade@gmail.com

1 Department of Geography, MES Abasaheb Garware College, Pune, Maharashtra 411004, India

2 Department of Statistics, MES Abasaheb Garware College, Pune, Maharashtra 411004, India

3 Department of Economics, MES Abasaheb Garware College, Pune, Maharashtra 411004, India between CPI and Per Capita Net State Domestic Product (PCNSDP) and size of population were performed and these are statistically significant. Findings are pointing out that, there is need for serious attention in populous and economic developed states and UTs of India.

Keywords COVID-19 performance index - Economic and demographic factors $\cdot$ India $\cdot$ Pandemic $\cdot$ Spatial

\section{Introduction}

COVID-19 pandemic has adversely affected on health, economy and mobility of millions of people in the world. The virus has been named Severe Acute Respiratory Syndrome coronavirus 2 (SARS-COV-2) and the disease is called as COVID-19. Coronavirus has been derived its name from Latin word "corona" meaning crown. It is newly discovered and is a group of related RNA viruses that mainly cause diseases in mammals and birds. In humans, these viruses cause respiratory tract infections that can range from mild to lethal. Mild illnesses include some cases of the common cold while more lethal varieties can cause SARS-COV, Middle East Respiratory Syndrome coronavirus (MERS-COV), and COVID-19. Coronavirus outbreak became known on December 31, 2019 when China informed the World Health Organisation (WHO) about few unknown caused cases of pneumonia in Wuhan City of Hubei Province. On March 11, 2020 WHO declared COVID-19 as a pandemic [1]. In the initial weeks of the pandemic situation, India faced a serious threat of COVID19 outbreak and considering the high risk of infections and deaths, Indian government and local administrative put several anti-pandemic preventive measures like prohibition on transportation, personal hygiene measures, physical 
distancing, time to time nationwide strict lockdown, boosting of health infrastructure and large media campaign which further helped in mitigating the spread of the pandemic in the country [2].

In India, this pandemic has adversely affected on mental health, economy and mobility of people. Due to the immediate and timely actions taken by the governments, India's case fatality rate was initially among the lowest in the world and steadily declining. The probability of transmission is more in the highly urbanised regions due to high density of population, mobility and economic activities. Although several factors may play a key role in the spread of COVID-19, hence in the present study few important economic and demographic parameters have been considered to develop the COVID-19 Performance Index (CPI). The CPI is a quantitative measurement of the efforts made by a particular region to handle the pandemic situation, which reflects the states and UTs responsiveness towards the pandemic. CPI is an index between 0 (poor) and 100 (best), and it gives an instrument to compare the regions on their efforts to handle the pandemic. More number of confirmed cases, deaths in a particular region shows the poor performance to handle the pandemic. More tests are not only help to trace and treat the people but also helps to control the spread of infection. All these parameters are used to calculate the index. The size of CPI is positively related to the performance of the region. We have considered three independent groups of CPI i.e. poor $(<25)$, moderate $(25-75)$ and good performance $(>75)$.

The Lowy institute Sidney, Australia, has studied approximately 98 countries CPI [3]. The detailed geographical area-wise analysis of coronavirus disease of China country was provided by $\mathrm{Yu}$ et. al. [4]. They considered three independent strata of China such as: Wuhan, Hubei excluding Wuhan and China excluding Hubei. The collected cumulative numbers of confirmed cases of COVID-19 from respective Municipal health commissions and National Health Commissions were analyzed using second derivative approach. Using this method they predict the trend of COVID-19 across these strata. Regression model for assessing the impact of globalization for Pune city was developed by Kshirsagar and Kurade [5]. In which they used Pearson's correlation test, to identify statistically significant parameters. Duan et. al. [6] measured the vulnerability of coronavirus disease using Fragile States Index. It is a measure of vulnerability to COVID-19 pandemic situation, which reflects a country's responsiveness towards the dangerous events. Using R-software they developed a novel multiple regression model with total FSI score as a response variable and 12 predictors. Four different indicators such as: cohesion, economic, political, and social and cross cutting indicators from 146 countries across 6 WHO regions were analyzed using one way analysis of variance (ANOVA) technique.

The basic fundamentals of COVID-19 were provided by Lamberghini and Testai [7]. They highlighted on various component of COVID-19 disease such as, viral cycle, structure, epidemiology, transmission, timeline, pathogenesis, diagnosis and treatment. The chest CT findings of 51 confirmed COVID-19 cases across 16 to 76 years from China were analyzed using Stata software by Song et. al. [8]. A detailed review of COVID-19 disease since its inception was done by Yuki et. al. [9]. In this review COVID-19 patients were classified across mild, moderate, severe and critical asymptomatic groups. Costantini and Mazzotti [10] provided COVID-19 Peritraumatic Distress Index (CPDI) for Italy. This refers to anxiety, depression, specific phobias, cognitive change, avoidance and compulsive behaviour, physical symptoms and loss of social functioning among the confirmed cases of COVID-19. They classified the distress index whose ranges from 0 to 100 into three different groups such as, no distress if score $<28$, mild to moderate distress if score between 28 and 51 and severe distress if score $>51$.

Salisu and Akanni [11] constructed a Global Fear Index (GFI) for COVID-19 patients. GFI measured the daily concerns and emotions on the spread and severity of COVID-19 since the pandemic declaration. It was a composite index of two factors viz., reported cases and reported deaths. While designing GFI, equal weights were assigned to each factor. It was derived on a scale of 0 to 100 , indicating the absence and presence of extreme fear/panic. A composite index of vulnerability at the state and district levels of India based on 15 indicators across the five domains as: socioeconomic, demographic, housing and hygiene, epidemiological, and health system were designed by Acharya and Porwal [12]. A map using GIS software displaying number of COVID-19 confirmed cases in India and vulnerability index was provided. They have computed the vulnerability indices for Indian states and union territories (UTs), and 640 districts. Also, a reliability of the vulnerability index using Cronbacks $\alpha(0<\alpha<1)$ was computed. Mohanty [13] commented on the vulnerability index to COVID-19 pandemic across geographies in India. He pointed that, the vulnerability index represents a risk of consequences of the infection across India. In particular, India accounts about 6\% global COVID-19 infections and the disease has spread from large cities to smaller towns as well as rural areas. Mishra et. al. [14] developed COVID vulnerability index. For the development, they have considered various parameters such as, density of population (persons per square $\mathrm{km}$ ), dilapidated residence, no exclusive room, main source of drinking water, number of households having no toilet facility, drinking water from untreated source. For experimental purpose four metro 
Fig. 1 Confirmed cases of COVID-19 in India (where Mizoram (MZ), Dadra and Nagar Haveli (DN), Andaman and Nicobar Islands (AN), Arunachal Pradesh (AR), Sikkim (SK), Ladakh (LA), Odisha (OR), Arunachal Pradesh (AR), Punjab (PB), Jharkhand (JH), Chandigarh (CH), Kerala (KL), Puducherry (PY), Meghalaya (ML), Uttar Pradesh (UP), Tripura (TR), Uttarakhand (UT), Bihar (BR), Telengana (TG), Nagaland (NL), Madhya Pradesh (MP), Goa (GA), Tamil Nadu (TN), West Bengal (WB), Delhi (DL), Jammu and Kashmir (JK), Rajasthan (RJ), Assam (AS), Gujarat (GJ), Manipur (MN), Andhra Pradesh (AP), Himachal Pradesh (HP), Chhattisgarh (CT), Haryana (HR), Karnataka (KA), Maharashtra (MH))

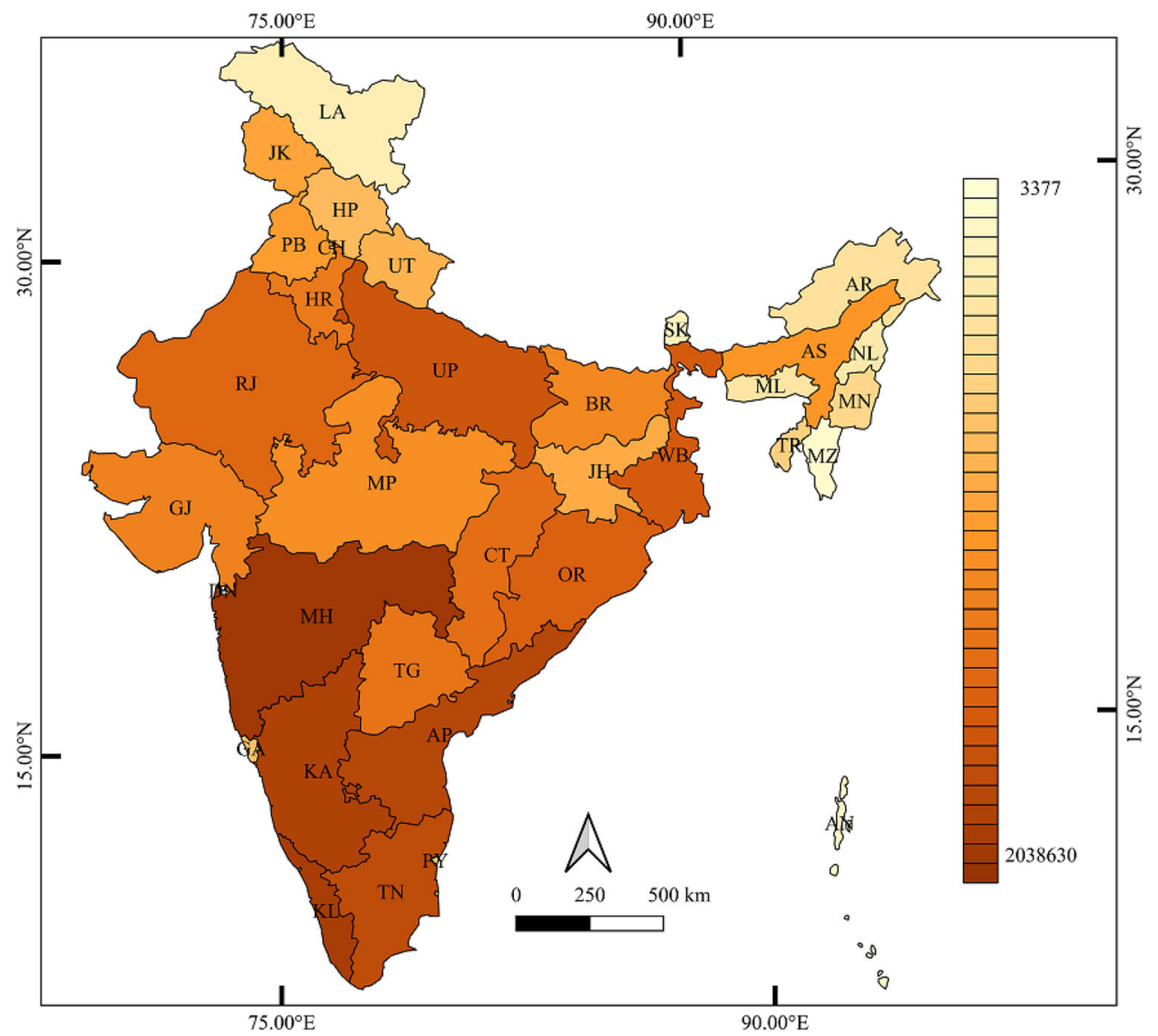

cities in India: Mumbai, Delhi, Chennai and Kolkata were considered.

Sarkar and Chouhan [15] assessed district level wise COVID-19 vulnerability in India. Various indicators were used for the vulnerability assessment. For the decision purpose of the vulnerability, all indicators were selected for principal component analysis with varimax rotation. The effect of lockdown and COVID-19 pandemic situation on air quality of Delhi city in India were studied by Mahato et. al. [16]. Various air pollutants were considered for the study. The detailed review, how India deal with economy, human living and environment during and post COVID-19 pandemic was provided by Ghosh et. al. [17]. The social distancing and strict 68 days of four phased nationwide lockdown according to WHO norms had an additional impact on these three factors in states and UTs of India. They tinted that, SARS-COV-2 is the root cause behind the coronavirus infection and it has about $96 \%$ identical to a bat derived SARS like coronavirus. The impact of lockdown on air quality in India during COVID-19 pandemic was given by Singh and Chauhan [18]. They have considered five major cities in India viz., Delhi, Kolkata, Mumbai, Chennai and Hyderabad where US embassies are located. Sarkar et. al. [19] modelled and forecasted the COVID-19 pandemic situation in India across various states. Das et. al. [20] modelled the effect of area deprivation on COVID-19 incidences for the case study of Chennai city. They highlighted various parts of the city which are in risk due to COVID-19. Using regression analysis they established the influence of area deprivation on COVID-19 incidences.

Coronavirus is a matter of biological science, but demographic and economic factors are among the responsible factors to spread the coronavirus. The spread of coronavirus is not uniform across the India due to these factors. The present study seeks to assess the anti-pandemic measures taken by the various states and UTs of India. The aim of the paper is to understand how the disease spread in India. Once the responsible parameters to the spread of coronavirus are identified, related measures can be adopted. The succeeded measures adopted by few regions can be applied in the severely affected regions to handle the pandemic. Major objective of the study is to calculate CPI for each state and UT of India, as an instrument for the comparison and to find out demographic and economic factors responsible for the spread of coronavirus. The rest of the paper is organized as: Sect. 2 describes the study area of the present study. Details about the collected data and research methods used in the study will be explained in Sect. 3. The computation of CPI, spatial representation of 
Fig. 2 Confirmed deaths of COVID-19 in India

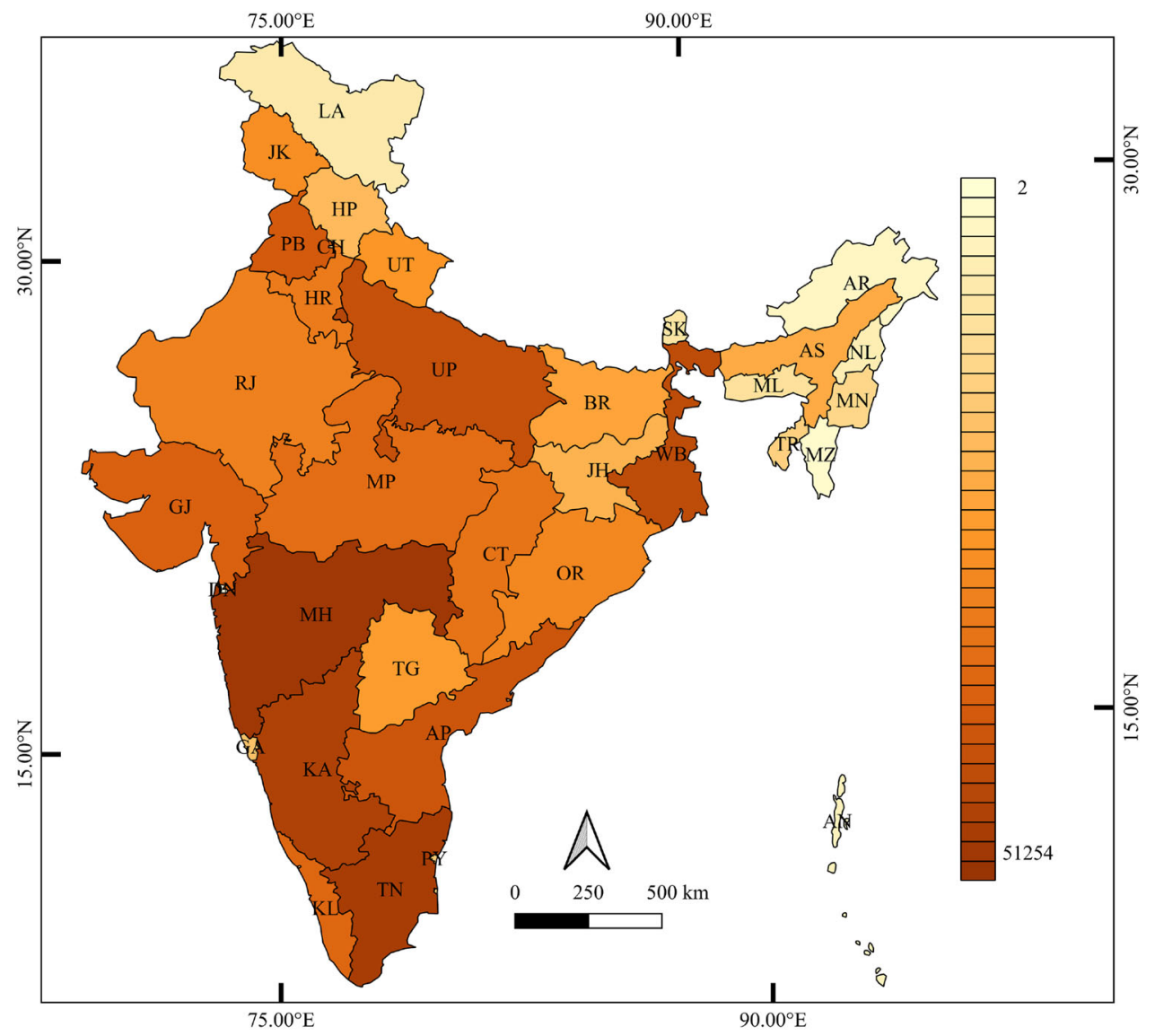

CPI for India and discussion of the obtained results by considering various parameters used in the study explained in Sect. 4. In the same Section, development of the best regression model for predicting CPI of India is also presented. In Sect. 5, we summarize the contribution of this study and point out the future direction.

\section{Study area}

India in Asia comprises 28 states and 8 union territories lying entirely in the northern hemisphere. It extends between 804' N and 3706' $\mathrm{N}$ latitude and 6807' E 97,025' $\mathrm{E}$ longitude. It is the world's seventh largest country in terms of geographical area and second largest in terms of a population of about 1.38 billion as of 2018. India is the world's second largest country in terms of population [21]. The nationwide strict lockdown due to COVID-19 pandemic has a huge impact on small, medium and large enterprises of the country, which led to huge decline in the Indian Economy [17]. The first case of COVID-19 in India was found in January 2020 in Kerala [22]. Most of the coronavirus cases in early months of 2020 in India originated abroad rather than being transmitted within the country. As of February 5, 2021, there were around
10.9 million confirmed COVID-19 cases out of which 10.6 million have recovered successfully [22]. More than 0.15 million people died due to COVID-19 infection in India.

In the initial period, several cases of pneumonia were reported in India and its spread and increase was abrupt. This initial rate of spread was high, unprecedented and different in every state and UT of India. At the outset, the cause of this disease was not properly recognised. Currently as far as confirmed cases of COVID-19 are concerned, India is the first in Asia and second highest country in the world after the United States of America (USA) [21]. The confirmed cases and deaths of COVID-19 in India are shown in Figs. 1 and 2 respectively. Considering the rapid increase in the number of cases of COVID-19 and following the guidelines of $\mathrm{WHO}$, the Indian government declared that the recent surge of the disease requires immediate health emergency [2]. These anti-pandemic measures have produced encouraging results and since October 2020, India has been recording steady decline in the number of daily deaths [22]. However, due to unlock process in India and the emergence of new variants of the coronavirus infection, the country has faced second wave of COVID-19 in the mid of March 2021. On April 9, 2021 
Table 1 COVID-19 Performance index (CPI) indicators

\begin{tabular}{lll}
\hline Sr. No & Indicator & Indicator code \\
\hline 1 & Confirmed cases & CC \\
2 & Confirmed deaths & CD \\
3 & Per million confirmed cases & PMCC \\
4 & Per million confirmed deaths & PMCD \\
5 & Tests per thousand & TPT \\
6 & Confirmed cases in proportion of test & CCPT \\
\hline
\end{tabular}

the highest number of COVID-19 cases (0.145 million) has been identified across India [23].

\section{Data and research methods}

In the present study, an attempt is made to assess the responsiveness of states and UTs of India, to mitigate the adverse effects of COVID-19 pandemic by analyzing and assessing the CPI. Six variant independent indicators of COVID-19 (Table 1) are used for computation of CPI for each state and UT of India according to the Ministry of Health and Family Affaires, Government of India. It is composed in the form of moving average after 100th registered COVID-19 case for respective states and UTs of India. The dates of 100th registered COVID-19 confirmed cases for each state is different i.e. Maharashtra and Kerala are the first and Meghalaya is the last state to registered the 100th COVID-19 case on March 25, 2020 and July 8, 2020 respectively. Hence, the present study considers total 211 days between March 25, 2020 and February 5, 2021 for the computation of CPI. Lakshadweep is excluded from the assessment as the numbers of cases in this UT is relatively low.

Fourteen day moving average of daily new figures is computed for the six independent indicators (Table 1) after the 100th confirmed case for each state and UT. The rank has been given on the basis of these individual moving averages to the state and UT. An average of the rankings across the six indicators are normalised for each state and UT to produce CPI between 0 (poor) and 100 (good) [10]. It is expressed by using Eqs. 1, 2, 3, 4

$$
\begin{aligned}
C P I_{j}= & \frac{1}{\text { Range }}\left(A v g \cdot \left(R\left[\frac{1}{n} \sum_{i=j}^{n} C C_{i}\right]+R\left[\frac{1}{n} \sum_{i=j}^{n} C D_{i}\right]+R\left[\frac{1}{n} \sum_{i=j}^{n} P M C C_{i}\right]\right.\right. \\
& \left.\left.+R\left[\frac{1}{n} \sum_{i=j}^{n} P M C D_{i}\right]+R\left[\frac{1}{n} \sum_{i=j}^{n} T P T_{i}\right]+R\left[\frac{1}{n} \sum_{i=j}^{n} C C P T_{i}\right]\right)\right) \\
C P I_{j+1}= & \frac{1}{\text { range }}\left(A v g .\left(R\left[\frac{1}{n} \sum_{i=j+1}^{n} C C_{i}\right]+R\left[\frac{1}{n} \sum_{i=j+1}^{n} C D_{i}\right]+R\left[\frac{1}{n} \sum_{i=j+1}^{n} P M C C_{i}\right]\right.\right. \\
& \left.\left.+R\left[\frac{1}{n} \sum_{i=j+1}^{n} P M C D_{i}\right]+R\left[\frac{1}{n} \sum_{i=j+1}^{n} T P T_{i}\right]+R\left[\frac{1}{n} \sum_{i=j+1}^{n} C C P T_{i}\right]\right)\right) \\
C P I_{k}= & \frac{1}{\text { range }}\left(A v g .\left(R\left[\frac{1}{n} \sum_{i=k-14}^{n} C C_{i}\right]+R\left[\frac{1}{n} \sum_{i=k-14}^{n} C D_{i}\right]+R\left[\frac{1}{n} \sum_{i=k-14}^{n} P M C C_{i}\right]\right.\right. \\
& \left.\left.+R\left[\frac{1}{n} \sum_{i=k-14}^{n} P M C D_{i}\right]+R\left[\frac{1}{n} \sum_{i=k-14}^{n} T P T_{i}\right]+R\left[\frac{1}{n} \sum_{i=k-14}^{n} C C P T_{i}\right]\right)\right)
\end{aligned}
$$

\begin{tabular}{|c|c|c|c|c|c|}
\hline $\begin{array}{l}\text { Sr. } \\
\text { No. }\end{array}$ & Parameter & Category & Criteria & State codes & $\begin{array}{l}\text { No. of } \\
\text { states }\end{array}$ \\
\hline \multirow[t]{3}{*}{1} & \multirow[t]{3}{*}{ Size of population (2020) } & Small & $<10$ Million & LA, AN, DN, SK, CH, MZ, PY, AR, GA, NL, MN, ML, TR, HP & 14 \\
\hline & & Medium & $\begin{array}{l}10-50 \\
\text { Million }\end{array}$ & UT, JK, DL, HR, CT, PB, AS, KL, TG, JH, OR & 11 \\
\hline & & Large & $>50$ Million & AP, GJ, KA, TN, RJ, MP, WB, MH, BR, UP & 10 \\
\hline \multirow[t]{2}{*}{2} & \multirow[t]{2}{*}{$\begin{array}{l}\text { PCNSDP at current price } \\
(2018-19)\end{array}$} & Low & $\begin{array}{l}<\text { National } \\
\text { average }\end{array}$ & $\begin{array}{l}\text { DN, LA, BR, UP, JH, MN, AS, ML, MP, JK, CT, OR, WB, RJ, TR, } \\
\text { NL }\end{array}$ & 16 \\
\hline & & High & $\begin{array}{l}>\text { National } \\
\text { average }\end{array}$ & $\begin{array}{l}\text { AR, MZ, AP, PB, AN, HP, MH, TN, GJ, UT, KL, TG, KA, PY, HR, } \\
\text { CH, DL, SK, GA }\end{array}$ & 19 \\
\hline \multirow[t]{2}{*}{3} & \multirow[t]{2}{*}{$\begin{array}{l}\text { Level of urbanisation } \\
\text { (2018) }\end{array}$} & Low & $\begin{array}{l}<\text { National } \\
\text { average }\end{array}$ & $\begin{array}{l}\text { HP, BR, AS, OR, ML, UP, AR, CT, JH, RJ, SK, JK, TR, MP, NL, } \\
\text { AP, MN, UT }\end{array}$ & 18 \\
\hline & & High & $\begin{array}{l}>\text { National } \\
\text { average }\end{array}$ & $\begin{array}{l}\text { WB, HR, PB, AN, KA, TG, GJ, MH, KL, TN, MZ, DN, GA, PY, LA, } \\
\text { CH, DL }\end{array}$ & 17 \\
\hline \multirow[t]{2}{*}{4} & \multirow[t]{2}{*}{$\begin{array}{l}\text { Density of population } \\
\text { (2018) }\end{array}$} & Low & $\begin{array}{l}<\text { National } \\
\text { average }\end{array}$ & $\begin{array}{l}\text { LA, AR, AN, MZ, SK, NL, MN, HP, ML, CT, UT, RJ, MP, OR, JK, } \\
\text { AP, GJ, TG, KA, TR, MH }\end{array}$ & 21 \\
\hline & & High & $\begin{array}{l}>\text { National } \\
\text { average }\end{array}$ & GA, AS, JH, PB, TN, HR, UP, KL, DN, WB, BR, PY, CH, DL & 14 \\
\hline
\end{tabular}

Table 2 Parameters and their categories 
Table 3 CPI of States and UTs and their Rank

\begin{tabular}{|c|c|c|c|c|c|c|c|c|}
\hline \multirow[t]{2}{*}{ Rank } & \multirow[t]{2}{*}{ States and UTs with Code } & \multicolumn{6}{|c|}{ Averages till February 5, 2021} & \multirow[t]{2}{*}{ CPI } \\
\hline & & $\mathrm{CC}$ & $\mathrm{CD}$ & PMCC & PMCD & TPT & CCPT $(\%)$ & \\
\hline 1 & Mizoram (MZ) & 20 & 0 & 16 & 0 & 1 & 25 & 80.82 \\
\hline 2 & Dadra and Nagar Haveli (DN) & 15 & 0 & 25 & 0 & 0 & 5 & 78.06 \\
\hline 3 & Andaman and Nicobar Islands (AN) & 23 & 0 & 56 & 1 & 2 & 11 & 75.59 \\
\hline 4 & Arunachal Pradesh (AR) & 79 & 0 & 50 & 0 & 1 & 4 & 69.72 \\
\hline 5 & Jharkhand (JH) & 511 & 5 & 1 & 0 & 0 & 3 & 65.95 \\
\hline 6 & Kerala (KL) & 1714 & 6 & 48 & 0 & 1 & 5 & 64.76 \\
\hline 7 & Meghalaya (ML) & 65 & 1 & 19 & 0 & 0 & 53 & 62.47 \\
\hline 8 & Tripura (TR) & 155 & 2 & 37 & 0 & 1 & 5 & 61.63 \\
\hline 9 & Bihar (BR) & 1080 & 6 & 9 & 0 & 0 & 4 & 60.47 \\
\hline 10 & Nagaland (NL) & 56 & 0 & 25 & 0 & 0 & 13 & 59.25 \\
\hline 11 & Jammu and Kashmir (JK) & 451 & 7 & 33 & 1 & 1 & 4 & 58.18 \\
\hline 12 & Assam (AS) & 1017 & 5 & 29 & 0 & 1 & 4 & 57.87 \\
\hline 13 & Manipur (MN) & 133 & 2 & 43 & 1 & 1 & 6 & 57.70 \\
\hline 14 & Himachal Pradesh (HP) & 242 & 4 & 32 & 1 & 0 & 7 & 57.58 \\
\hline 15 & Haryana (HR) & 824 & 9 & 29 & 0 & 0 & 6 & 52.33 \\
\hline 16 & Rajasthan (RJ) & 916 & 9 & 11 & 0 & 0 & 5 & 52.27 \\
\hline 17 & Sikkim (SK) & 28 & 1 & 41 & 1 & 0 & 12 & 52.05 \\
\hline 18 & Ladakh (LA) & 45 & 1 & 155 & 2 & 2 & 41 & 52.00 \\
\hline 19 & Odisha (OR) & 1487 & 8 & 32 & 0 & 1 & 5 & 51.88 \\
\hline 20 & Punjab (PB) & 643 & 20 & 21 & 1 & 0 & 13 & 51.03 \\
\hline 21 & Chandigarh $(\mathrm{CH})$ & 83 & 1 & 71 & 1 & 1 & 12 & 50.56 \\
\hline 22 & Puducherry (PY) & 181 & 3 & 128 & 2 & 2 & 10 & 50.49 \\
\hline 23 & Uttar Pradesh (UP) & 398 & 7 & 35 & 1 & 1 & 6 & 48.87 \\
\hline 24 & Uttarakhand (UT) & 2246 & 33 & 9 & 0 & 0 & 3 & 49.15 \\
\hline 25 & Telengana (TG) & 1114 & 6 & 29 & 0 & 1 & 11 & 47.99 \\
\hline 26 & Madhya Pradesh (MP) & 808 & 14 & 9 & 0 & 0 & 48 & 46.01 \\
\hline 27 & Gujarat (GJ) & 819 & 18 & 13 & 0 & 0 & 6 & 45.51 \\
\hline 28 & Andhra Pradesh (AP) & 3888 & 32 & 72 & 1 & 1 & 28 & 43.17 \\
\hline 29 & Chhattisgarh (CT) & 1241 & 15 & 42 & 1 & 0 & 8 & 42.87 \\
\hline 30 & Karnataka (KA) & 3852 & 52 & 57 & 1 & 1 & 8 & 40.05 \\
\hline 31 & Goa (GA) & 242 & 4 & 152 & 2 & 1 & 14 & 39.92 \\
\hline 32 & West Bengal (WB) & 1865 & 34 & 19 & 0 & 0 & 7 & 36.73 \\
\hline 33 & Tamil Nadu (TN) & 3396 & 52 & 44 & 1 & 1 & 8 & 33.70 \\
\hline 34 & Delhi (DL) & 1753 & 30 & 94 & 2 & 1 & 10 & 32.03 \\
\hline 35 & Maharashtra (MH) & 7666 & 202 & 62 & 2 & 0 & 17 & 15.45 \\
\hline
\end{tabular}

Overall CPI $=\frac{1}{k}\left(C P I_{j}+C P I_{j+1}+\cdots+C P I_{k}\right)$

where $\mathrm{j}=1$ (first day of Sth state after their hundredth case), $\mathrm{R}=$ rank on the basis of respective indicator across the state and UT, $\mathrm{n}=14, \mathrm{k}=211$ and $\mathrm{S}=1,2,3, \ldots, 35$.

For comparative purpose, we have considered various categories of the parameters (Table 2). These are size of population (Small, Medium and Large), Per Capita Net State Domestic Product (PCNSDP) (Low and High), level of urbanisation (Low and High), and density of population
(Low and High). The size of population is considered as of year 2020, PCNSDP at current price of 2018-19 and density of population and level of urbanisation as of year 2018. These parameters help to better understand the transmission level of the infectious virus, as all these parameters are more responsible to the spread of the virus directly and indirectly. The national average of PCNSDP ( $₹$ 0.127 million), density (455 per square $\mathrm{km}$ ) and urbanisation $(34.03 \%)$ are considered as a benchmark for the category. Data regarding the categories of each parameter and 
Fig. 3 CPI of states and UTs of India

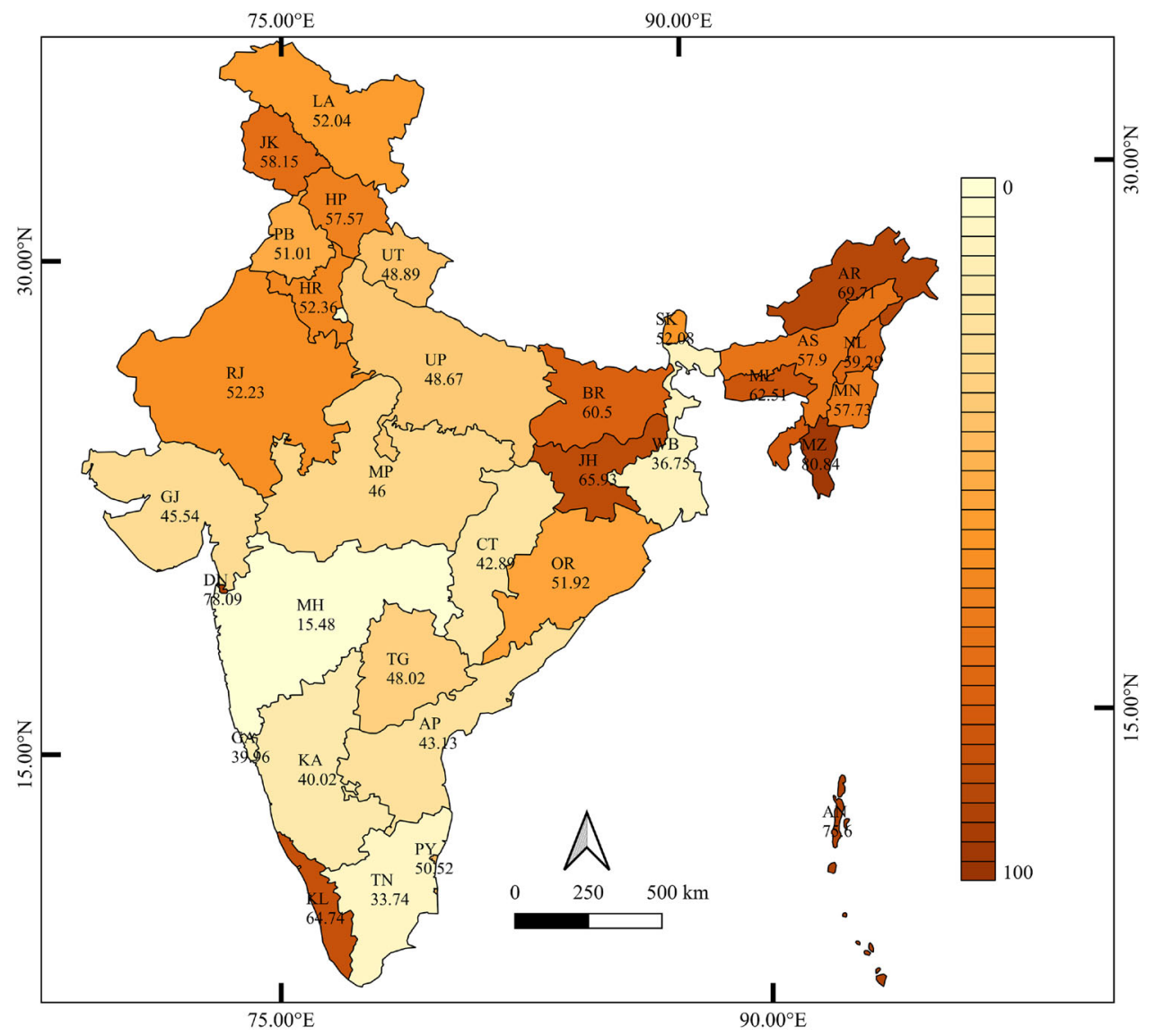

Table $4 \mathrm{CC}$ and $\mathrm{CD}$ of selected districts of Maharashtra as of February 5, 2021

\begin{tabular}{llll}
\hline Sr. No & District & Confirmed cases & Confirmed deaths \\
\hline 1 & Pune & $390,574(19)$ & $7998(16)$ \\
2 & Mumbai & $311,019(15)$ & $11,384(22)$ \\
3 & Thane & $270,113(13)$ & $5777(11)$ \\
4 & Nagpur & $137,035(7)$ & $3373(7)$ \\
5 & Nashik & $122,088(6)$ & $2000(4)$ \\
Sub Total & & $1,230,829(60)$ & $30,532(60)$ \\
Maharashtra & $2,038,630(100)$ & $51,255(100)$ \\
\hline
\end{tabular}

Value in the parentheses shows percentage of Maharashtra

all other data used in this study has been collected from the official sources [2, 21, 23, 24].

Karl Pearson's correlation test used to assess the correlation between CPI and the parameters listed in Table 2. The ordinary least square (OLS) regression procedure and the correlation test [5] have been used to determine the significant explanatory variables or predictors among the above parameters to develop the best regression model. The model is developed by taking CPI as a dependent variable and PCNSDP, density of population, level of urbanization and population size as independent variables. $\mathrm{R}$ (4.0.4) software has been used for statistical analysis. In GIS (Geographic Information System) environment, spatial and non-spatial data can be gathered, stored, managed, analysed and displayed. In the present study, QGIS (3.16.3) is used for spatial analysis of the parameters under consideration.

\section{Result and discussion}

Based on the research method explained in the preceding section, CPI was computed as shown in Table 3 and spatially shown in Fig. 3. Mizoram ranks first with 80.82 followed by Dadra Nagar Haveli, 78.06 and Andaman Nicobar, 75.59. There are 8 states and 2 UTs in the top ten rankings and 9 states and $1 \mathrm{UT}$ in last ten. The average CPI for the top ten good performers is 67.87 and for last ten poor performers is 37.54. Parameter wise averages of top ten good performers comprised around 16\% of India's total population, PCNSDP (₹ 0.113 million), level of urbanisation $(31.01 \%)$ and density of population (317) are relatively lower than the national average. The last ten poor performing states and UTs consist of around 45\% of India's total population, PCNSDP (₹ 0.202 million), level of 
Fig. 4 Distribution of states and UTs according to size of population and their $\mathrm{CPI}$

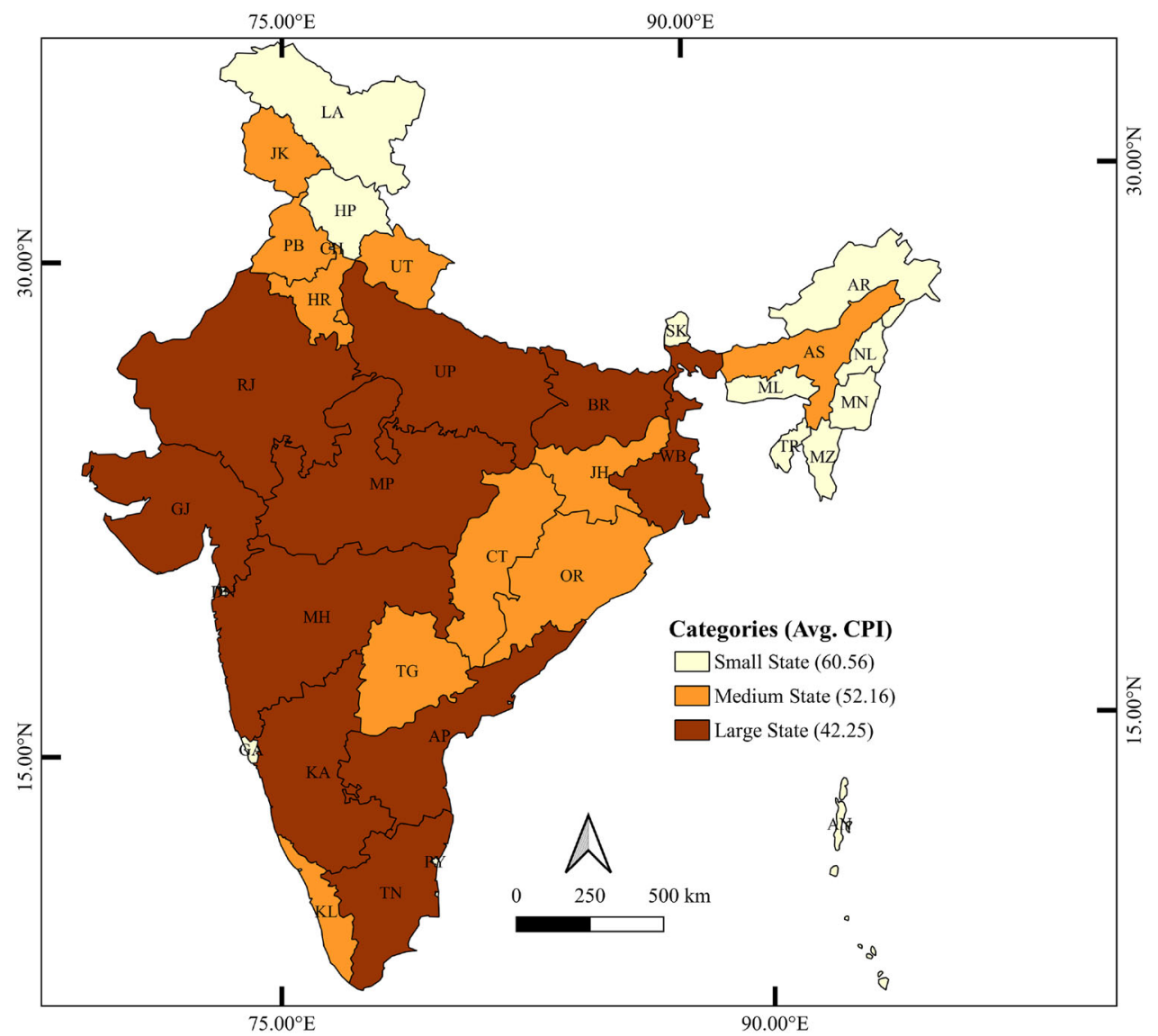

Table 5 Average CPI within categories

\begin{tabular}{llll}
\hline Sr. No & Parameter & Category & CPI \\
\hline 1 & Size of population & Small & 60.56 \\
& & Medium & 52.16 \\
& & Large & 42.25 \\
2 & PCNSDP & Low & 55.78 \\
& & High & 50.09 \\
3 & Level of urbanisation & Low & 55.39 \\
& & High & 49.82 \\
4 & \multirow{3}{*}{ Density of population } & Low & 53.38 \\
& & High & 51.65 \\
\hline
\end{tabular}

urbanisation (36.05\%) and density of population (1389). All these are more than the national average of respective parameters taken into consideration.

Average CPI of states and UTs are 51.91 and 56.46 respectively, which shows the performances of UTs are better than those of states due to considered parameters. According to Table 3, economically advanced states and UTs show poor performance. Size of population, level of urbanization and density of population in these states and UTs are higher compared to others. Maharashtra state has low CPI among all states and UTs. The Maharashtra state has total 2.04 million confirmed cases and 0.0513 million confirmed deaths till February 5, 2021. Out of these confirmed cases and confirmed deaths, the metropolitan districts of Maharashtra viz., Pune, Mumbai, Thane, Nagpur and Nashik comprises $60 \%$ confirmed cases and confirmed deaths respectively (Table 4). Around 14 small states and UTs in terms of population have highest average CPI i.e. 60.56 among the category, whereas average CPI of 11 medium and 10 large states and UTs are 52.16 and 42.25 respectively (Fig. 4 and Table 5). This result shows populous states and UTs have low performance index as probability of transmission in high population areas is always high. PCNSDP shows that around 19 high income states and UTs have low CPI (Fig. 5 and Table 5). Economically advanced regions always have high PCNSDP and work as pull factor for the mobility of population for many reasons. Due to the large economic and industrial activities, mobility in these regions is always high. High mobility of population is considered as one of major cause of spread and infection of COVID-19. Metropolitan cities of India like Delhi, Ahmadabad, Mumbai, Pune and Kolkata etc. are the best examples as they are affected most 
Fig. 5 Distribution of states and UTs according to PCNSDP and their CPI

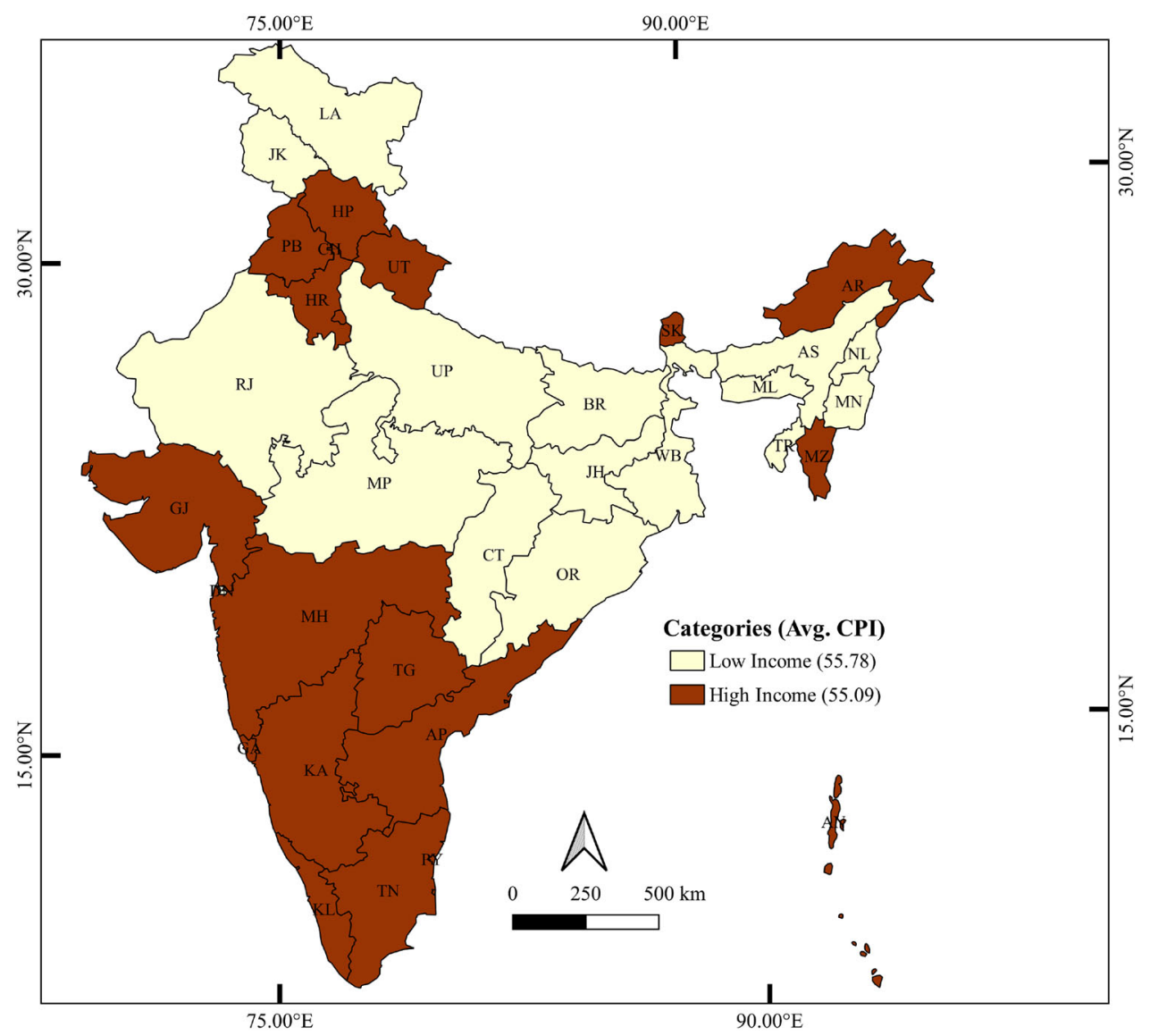

due to coronavirus. The spatial distribution of CPI in accordance with level of urbanization of states and UTs in India are shown in Fig. 6. Similar result is also observed in terms of density of population, where average CPI of 21 states and UTs of low density of population is 53.89. Total 14 states and UTs with high density have 51.65 CPI (Fig. 7 and Table 5). States and UTs with large size of population and high density show low CPI mainly because the more movement and contacts of the people more the chances of infection. Large size of population, high density, heterogeneity and high mobility are some of the characteristics of urbanisation all over the world. These characteristics are also favourable to the spread of coronavirus. It is validated from the Table 5. There are 18 states and UTs with less percentage of urbanisation than India's average national level of urbanisation, which has better CPI (55.37) than 17 states and UTs with high percentage of urbanisation (49.85). According to the three independent categories of
CPI viz., poor, moderate and good, the spatial distribution of states and UTs in India is shown in Fig. 8.

Average CPI according to size of population and economic status is shown in Table 6. Using this, we conclude that, CPI for small and low income states and UTs is higher and for large states with high income have low average CPI. The average CPI for small and low income states and UTs is 61.85 . The outcome reveals that, these 6 states and UTs of this category handled the COVID-19 pandemic situation very well as compared with large and high income states and UTs. There are 5 states and UTs in large and high income category which comprises around $28 \%$ of India's total population and for these 5 states and UTs, PCNSDP is high than the national average. It reflects that, these states and UTs could not handle the COVID-19 pandemic situation due to various factors such as high density, high urbanization, high population and high eco- 
Fig. 6 Distribution of states and UTs according to level of urbanization with their CPI

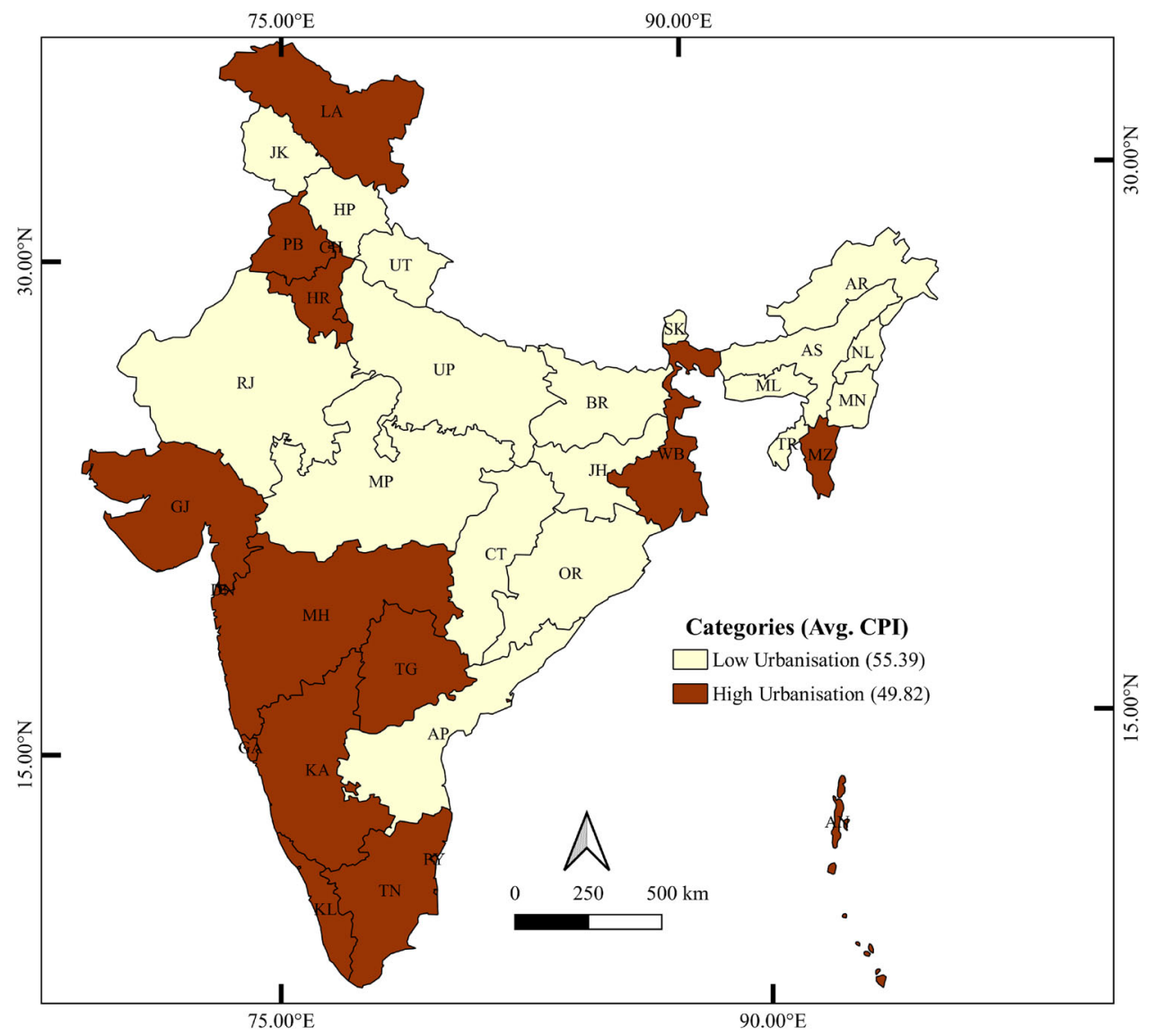

nomic growth which are the responsible factors for rapid transmission of the virus in these states.

The lowest CPI is 15.45 and it was found for the Maharashtra state. In Maharashtra state there are total cases are 7666 , out of which total deaths are 202 , which is very high during the study period. The Confirmed Cases in Proportion of Test (CCPT) for Maharashtra state is $17 \%$. There are 5 states and UTs viz., Meghalaya (53\%), Madhya Pradesh (48\%), Ladakh (41\%), Andhra Pradesh (28\%), and Mizoram (25\%), having high CCPT than Maharashtra. In Maharashtra, particularly the metropolitan cities such as Mumbai, Pune, Thane, Nagpur and Nashik are found to be more affected which results low CPI of the state. These districts account $60 \%$ (Table 4) deaths of total deaths of COVID-19 in Maharashtra during the study period. Table 4 shows the confirmed cases and deaths in 5 districts of Maharashtra out of 36 districts [22]. Maharashtra's total population is 12.08 million [24]; it is $9.34 \%$ of India's total population. As of February 5, 2021 Maharashtra recorded 2.04 million confirmed cases out which 1.231 million $(60 \%)$ cases are recorded in these districts. These metropolitan cities also known as industrial hubs of Maharashtra, comprise $39 \%$ of its population (Table 4). Mumbai is economic capital of India, accounts $6.16 \%$ of India's Economy, also contributing $10 \%$ of factory employment of India. These factors are responsible for the poor performance of Maharashtra. In Mumbai, BMC used chase the virus strategy and started to work from grass root level applying various stages like tracing, tracking, testing and treating. Dharavi, Mumbai, which was among the top ten COVID-19 hot spots in the country is spread over 2.5 square $\mathrm{km}$ area, with population density of 0.23 million per square $\mathrm{km}$ has also shown positive result and number of cases fall down rapidly due these efforts. Hence this 
Fig. 7 Distribution of states and UTs according to density of population with their CPI

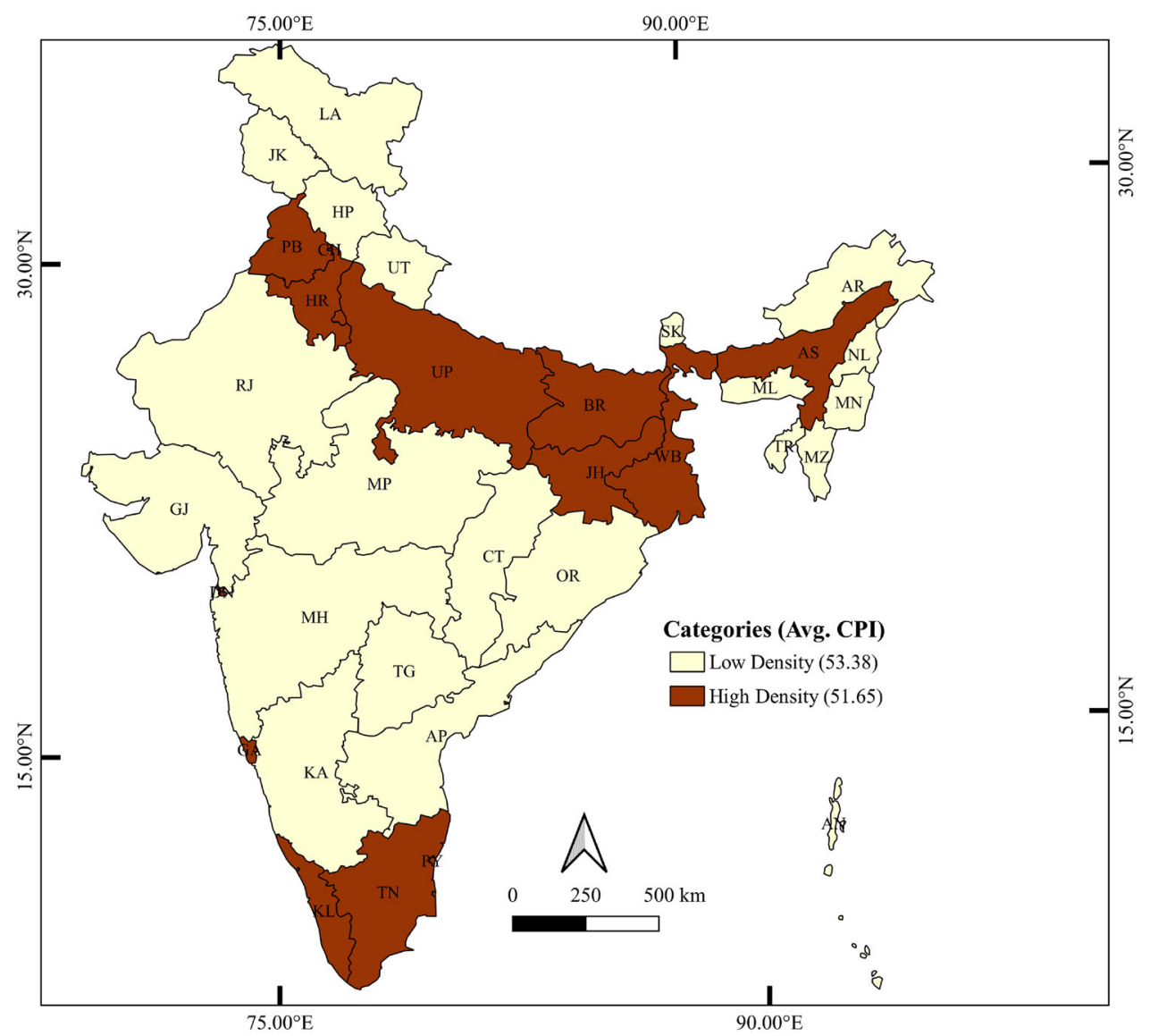

strategy of Mumbai BMC viz., Dharavi model of Maharashtra is much appreciated around the world.

The Karl Pearson's correlation coefficient is computed between CPI and each of the parameter (Table 2). The values are, for PCNSDP, $(\mathrm{r}=-0.377, p$ : 0.026), for density of population, $(\mathrm{r}=-0.217, p: 0.021)$, for level of urbanisation, $(\mathrm{r}=-0.236, p: 0.017)$ and for size of population, $(r=-0.418, p: 0.012)$. Thus, all correlation coefficients are negative and significant $(\alpha=0.05)$. For checking the significant predictors to predict the CPI of a state or UT an OLS regression model is built using $\mathrm{R}$ software. Thus, the results of a no-intercept term OLS regression model are reported in Table 7. From this table, density of population and level of urbanization are significant $(\alpha=0.05)$ to predict the CPI (dependent variable) with adjusted $\mathrm{R}^{2}=0.78$. The best regression model to predict the CPI of India is,

$C P I=1.184 *$ Level of Urbanization -0.008216

* Density of Population
The F-statistics value of the fitted model is 32.02 at 4 and 31 degrees of freedom with $p: 1.323 \mathrm{e}-10<\alpha$. The normality assumption of the fitted regression model was checked using Shapiro-Wilk test yielding $p: 0.665>\alpha$. Hence, assumption of normality is strongly satisfied. Also, Akaike Information Criteria (AIC) of the fitted model is computed and is shown at the bottom of Table 7. This indicates that, the fitted regression model is good for predicting the CPI of a state or UT by simply knowing the values of density of population and level of urbanization with relatively small error. For checking multicollinearity assumption of the fitted model, we have computed variance inflation factor (VIF) for each predictor and reported in Table 7. Thus, we conclude that, there is no serious problem of multicollinearity i.e., the linear dependence between the predictors (since $\mathrm{VIF}<5$ ) and the fitted model is adequate. 
Fig. 8 Categories of CPI according to states and UTs

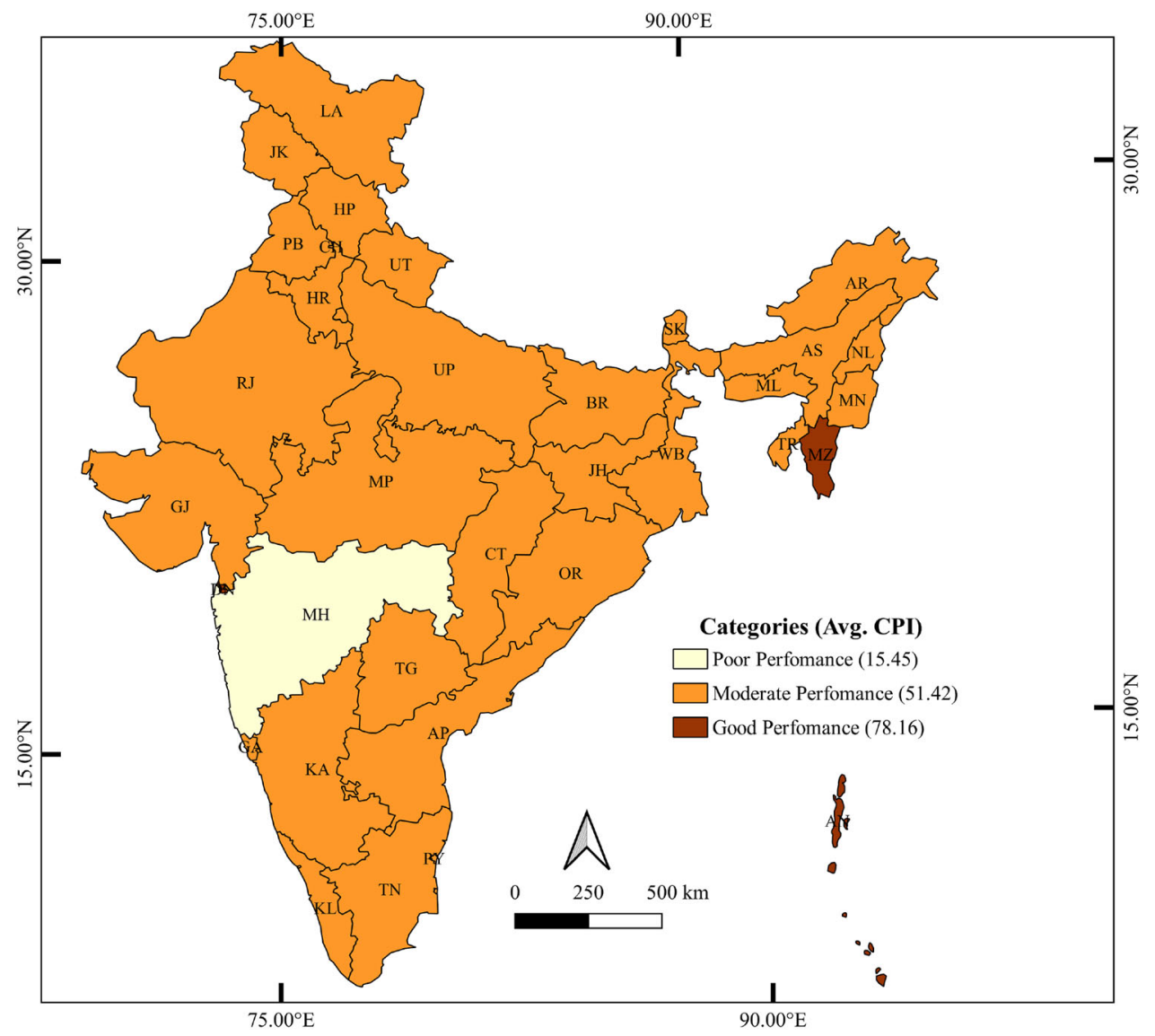

Table 6 CPI according to population size and economic status of the states

\begin{tabular}{llll}
\hline Category & Low income & High income & Total \\
\hline Small States & $61.85(6)$ & $59.59(8)$ & $60.56(14)$ \\
Medium States & $55.35(5)$ & $49.50(6)$ & $52.16(11)$ \\
Large States & $48.92(5)$ & $35.57(5)$ & $42.25(10)$ \\
Total & $55.78(16)$ & $50.09(19)$ & $52.69(35)$ \\
\hline
\end{tabular}

Note: number of states falls in the category shown in parentheses

Table 7 Values of regression coefficients and t-statistics of parameters

\begin{tabular}{llrll}
\hline Parameter & $\beta$ & \multicolumn{1}{l}{$t$-Stat } & $P$ value & VIF \\
\hline PCNSDP & $6.813 \mathrm{e}-05$ & 1.753 & 0.08948 & 1.088 \\
Size of population & $-5.549 \mathrm{e}-08$ & -0.586 & 0.56203 & 1.230 \\
Density of Population & $-\mathbf{8 . 2 1 6 e - 0 3}$ & $-\mathbf{3 . 0 6 2}$ & $\mathbf{0 . 0 0 4 5 2}$ & $\mathbf{2 . 7 2 9}$ \\
Level of Urbanisation & $\mathbf{1 . 1 8 4}$ & $\mathbf{4 . 6 1 5}$ & $\mathbf{6 . 4 6 e - 0 5}$ & $\mathbf{2 . 9 3 6}$ \\
\hline
\end{tabular}

$\overline{\mathrm{R}^{2}=0.8051 \text { and } \mathrm{AIC}=331.71 \text {. Bold values indicate significant }}$ parameters

\section{Conclusion}

The present study has been conducted to understand the comparative efforts made by the states and UTs to control the pandemic through CPI. The pandemic has formed as life-threatening and is considered as one of the most serious infection. From CPI, it is observed that the small populated states and UTs have taken more efforts to control the pandemic than large populated states and UTs. As far as urbanization and density of population is concerned, low density and less urbanised states and UTs has taken more efforts to control the pandemic. It is also found that, the states and UTs with low PCNSDP has been shown better performance during the pandemic. According to the guidelines of WHO, more the number of tests better will be the early control from rapid transmission of COVID-19. Lower confirmed cases in proportion to the test indicate the better control over the pandemic. Physical distancing, lockdown, improved health related infrastructure and large media campaign are some of the applied preventive measures which helped in mitigating the spread in the states and UTs. The results show that, spread of coronavirus is not uniform across India. The average CPI for all states and UTs of India is 52.69. The findings of the research may be 
able to assist policy makers on the eve of second wave and possible further waves of the pandemic.

Acknowledgements We are grateful to the Editor-in-Chief and anonymous reviewers for their meticulous comments and suggestions which helped us to improve the manuscript in the present stage. The authors are grateful to the Government of India for supporting data in this research.

Author contribution NA Conceptualization, Data collection, Formal Analysis, Investigation, Validation, Writing-introduction, methodology and editing, Approval of final article. SK Formal Analysis, Investigation, Validation, Writing-review, editing and original draft, Approval of final article.AS Investigation, Methodology, Software, Validation, Writing-study area and editing, Approval of final article.

Funding No funding received.

\section{Declarations}

Conflict of interest The authors declare that they have no conflict of interest.

\section{References}

1. World Health Organization (WHO), Coronavirus disease (COVID-19) outbreak situation. (2020). https://www.who.int/ emergencies/diseases/novel-coronavirus-2019 (Accessed February 5,2021 ).

2. Government of India. https://www.mygov.in/COVID-19(Acces sed February 5, 2021).

3. Lowy institute Covid Performance Index. https://interactives. lowyinstitute.org/ features/covid-performance (Accessed January 10, 2021)

4. Yu, B., Chen, X., Rich, S., Mo, Q., \& Yan, H. (2021). Dynamics of the coronavirus disease 2019 (COVID-19) epidemic in Wuhan City, Hubei Province and China: A second derivative analysis of the cumulative daily diagnosed cases during the first 85 days. Global Health Journal. https://doi.org/10.1016/j.glohj.2021.02. 001

5. Kshirsagar, M. B., \& Kurade, S. S. (2018). Globalization effect on college students for Pune city. Journal of applied science and computations, 5(10), 963-965.

6. Duan, Y., Ma, J., Huang, Y., Chen, X., \& Zheng, Z. J. (2021). State fragility and the coronavirus disease 2019 (COVID-19) Pandemic: An ecologic analysis of data from 146 countries. Global Health Journal. https://doi.org/10.1016/j.glohj.2021.02. 002

7. Lamberghini, F., \& Testai, F. D. (2021). COVID-19 fundamentals. The Journal of the American Dental Association. https://doi. org/10.1016/j.adaj.2021.01.014

8. Song, F., Shi, N., Shan, F., Zhang, Z., Shen, J., Lu, H., Ling, Y., Jiang, Y., \& Shi, Y. (2020). Emerging 2019 novel coronavirus (2019-nCoV) pneumonia. Radiology, 295(1), 210-217. https:// doi.org/10.1148/radiol.2020200274
9. Yuki, K., Fujiogi, M., \& Koutsogiannaki, S. (2020). COVID-19 pathophysiology: A review. Clinical immunology. https://doi.org/ 10.1016/j.clim.2020.108427

10. Costantini, A., \& Mazzotti, E. (2020). Italian validation of CoViD-19 peritraumatic distress Index and preliminary data in a sample of general population. Rivista di psichiatria, 55(3), 145151. https://doi.org/10.1708/3382.33570

11. Salisu, A. A., \& Akanni, L. O. (2020). Constructing a global fear index for the COVID-19 pandemic. Emerging Markets Finance and Trade, 56(10), 2310-2331. https://doi.org/10.1080/ 1540496X.2020.1785424

12. Acharya, R., \& Porwal, A. (2020). A vulnerability index for the management of and response to the COVID-19 epidemic in India: An ecological study. The Lancet Global Health, 8(9), e1142e1151. https://doi.org/10.1016/S2214-109X(20)30300-4

13. Mohanty, S. K. (2020). Contextualising geographical vulnerability to COVID-19 in India. The Lancet Global Health, 8(9), e1104-e1105. https://doi.org/10.1016/S2214-109X(20)30329-6

14. Mishra, S. V., Gayen, A., \& Haque, S. M. (2020). COVID-19 and urban vulnerability in India. Habitat international, 103, 102230.

15. Sarkar, A., \& Chouhan, P. (2021). COVID-19: District level vulnerability assessment in India. Clinical epidemiology and global health, 9, 204-215. https://doi.org/10.1016/j.cegh.2020. 08.017

16. Mahato, S., Pal, S., \& Ghosh, K. G. (2020). Effect of lockdown amid COVID-19 pandemic on air quality of the megacity Delhi India. Science of the Total Environment, 730, 139086. https://doi. org/10.1016/j.scitotenv.2020.139086

17. Ghosh, A., Nundy, S., \& Mallick, T. K. (2020). How India is dealing with COVID-19 pandemic. Sensors International, 1, 100021. https://doi.org/10.1016/j.sint1.2020.100021

18. Singh, R. P., \& Chauhan, A. (2020). Impact of lockdown on air quality in India during COVID-19 pandemic. Air Quality, Atmosphere \& Health, 13(8), 921-928. https://doi.org/10.1007/ s11869-020-00863-1

19. Sarkar, K., Khajanchi, S., \& Nieto, J. J. (2020). Modeling and forecasting the COVID-19 pandemic in India. Chaos, Solitons \& Fractals, 139, 110049.

20. Das, A., Ghosh, S., Das, K., Basu, T., Das, M., \& Dutta, I. (2020). Modeling the effect of area deprivation on COVID-19 incidences: A study of Chennai megacity, India. Public Health, 185, 266269. https://doi.org/10.1016/j.puhe.2020.06.011

21. United Nations, Department of Economic and Social Affairs, Population Division (2019). World Population Prospects 2019. https://www.un.org/development/ desa/publications/world-population-prospects-2019-highlights.html(Accessed July 21, 2021).

22. India COVID-19 tracker. (2020a). https://www.covid19india.org/ (Accessed February 5, 2021).

23. Worldometer. COVID-19 coronavirus pandemic, 2021, published online April 10.https://www.worldometers.info/coronavirus/ (Accessed July 21, 2021).

24. Census of India 2011. https://censusindia.gov.in/2011-provresults/prov_data_products_maha.html (Accessed February 5, 2021).

\section{Publisher's Note}

Springer Nature remains neutral with regard to jurisdictional claims in published maps and institutional affiliations. 